\title{
O Mercosul e a penhora da Casa
}

\author{
RICARDO SEITENFUS
}

$\mathrm{T}$ ORNOU-SE LUGAR comum associar o processo de construção do Mercado Comum do Sul (Mercosul) à palavra crise: crise em razão da incipiência das trocas comerciais, quando as economias dos Estados-membros atravessam turbulências; crise proveniente do desequilíbrio dessas trocas, fazendo com que os Estados adotem medidas unilaterais para remediá-las; crise de confiança entre os sócios, que não conseguem estabelecer estratégias comuns frente a terceiros Estados, e junto aos organismos internacionais; crise institucional do bloco, na medida em que o aparato organizacional permanece impregnado pelo voluntarismo político e pela incapacidade crônica de gerar produtos tangíveis; crise, enfim, pelo recorrente divórcio entre as sociedades dos Estados que compõem o Mercosul e o caráter essencialmente mercantilista do processo, que tende a afastá-las de seu horizonte de interesse.

No entanto, apesar das oscilações políticas e econômicas que afetaram em maior ou menor grau seus Estados-membros, desde o surgimento do Mercosul, em 1991, o bloco foi capaz de ser o eixo das relações exteriores da região, e constitui um forte referencial para a balança comercial. Além disso, a recorrência da crise é intrínseca a um organismo vivo que tenta conciliar interesses contraditórios. Nessa perspectiva, a crise pode ser sinal de saúde, pois somente ela desmascara os problemas e permite o seu enfrentamento. Ou seja, um processo de integração desprovido de crises seria artificial e, por conseguinte, sem futuro.

Tendo presente este quadro e estas percepções, é possível detectar, na atualidade, o surgimento de um novo cenário, no qual a suposta crise permanente do Mercosul cede lugar à possibilidade de transcendência, não tanto da crise mas do próprio processo de integração platino, tal como concebido originalmente. A partir desta constatação, encontra-se no centro do debate não mais os dilemas vinculados ao modelo e ao ritmo de integração adotados pelo Mercosul, mas sua existência como alternativa e instrumento de organização regional e de inserção internacional.

Para tentar entender a atual encruzilhada do Mercosul, o presente artigo perscruta o significado e o alcance da proposta de criação da Comunidade Sulamericana de Nações (Casa), que poderá vir a ser o locus de confluência dos diferentes processos de integração em curso na região. A seguir, busca situar o Mercosul neste contexto subcontinental, e propõe um exercício prospectivo sobre as possíveis mudanças estruturais no entorno sul-americano e suas conseqüências para as relações internacionais. 


\section{Os móveis e utensílios da Casa}

Inspirador de uma diplomacia voltada ao Sul, o presidente Lula concede à América do Sul uma atenção especial. Trata-se, segundo o Chanceler Celso Amorim, da "prioridade entre as prioridades" do Presidente Lula. Estas propícias condições permitem o renascimento da proposta de criação de uma Área de Livre Comércio Sul-americana (Alcsa), que havia sido sugerida na Presidência de Itamar Franco (1993-1994), sob a batuta do mesmo Amorim, então chanceler. Adotando uma nova sigla (Casa) e com outra roupagem, Brasília propõe a criação de um espaço coordenado de atuação coletiva na América do Sul.

Num primeiro momento, trata-se de um instrumento de natureza política capaz de transformar-se em foro no qual seriam identificados os problemas comuns e tomadas medidas coletivas para suplantá-los. Lamentavelmente, não deve haver engano (ou ilusão) sobre a utilização das expressões "comunidade" e "Nações". A primeira não deve ser interpretada em seu sentido jurídico ou econômico como sugere a experiência das Comunidades Européias - criadoras, inclusive, de um novo e revolucionário Direito. Na nossa cultura política, esta expressão não significa um maior engajamento no projeto coletivo, mas exatamente o seu contrário.

A segunda expressão não traduz a participação social (da Nação) no projeto proposto. Sua natureza é absolutamente estatal, pura emanação do Poder Executivo, e decorre essencialmente de uma vontade diplomática. Tal como ocorre com o Mercosul, a Casa enfrentará o desafio estruturante de transcender o insuficiente embora indispensável voluntarismo diplomático, e transformar-se num processo no qual se engajem as sociedades dos Estados-membros.

Quando do surgimento da Casa, na I Reunião de Chefes de Estados, realizada em Cuzco, foi estabelecido um programa de ação a indicar os objetivos e instrumentos dos quais disporia o novo arranjo subcontinental. Entre as principais metas não-econômicas destacam-se as seguintes:

- posições comuns, por meio da emissão de comunicados oficiais, frente às situações de crise institucional na região;

- intervenções conjuntas e apresentação de projetos comuns nos organismos internacionais;

- constituição de um embrião de coordenação política entre todos os países da América do Sul;

- isenção de visto de turista e de passaporte para os nacionais dos Estadosmembros;

- possibilidade de estabelecimento de um serviço de interconexão (roaming) sul-americano, e de uma estrutura de suporte (backbone) sul-americana para os serviços de comunicação e Internet;

- negociação de instrumentos sobre o reconhecimento de títulos e diplomas, e elaboração de um programa de cooperação científica e tecnológica na América do Sul. 


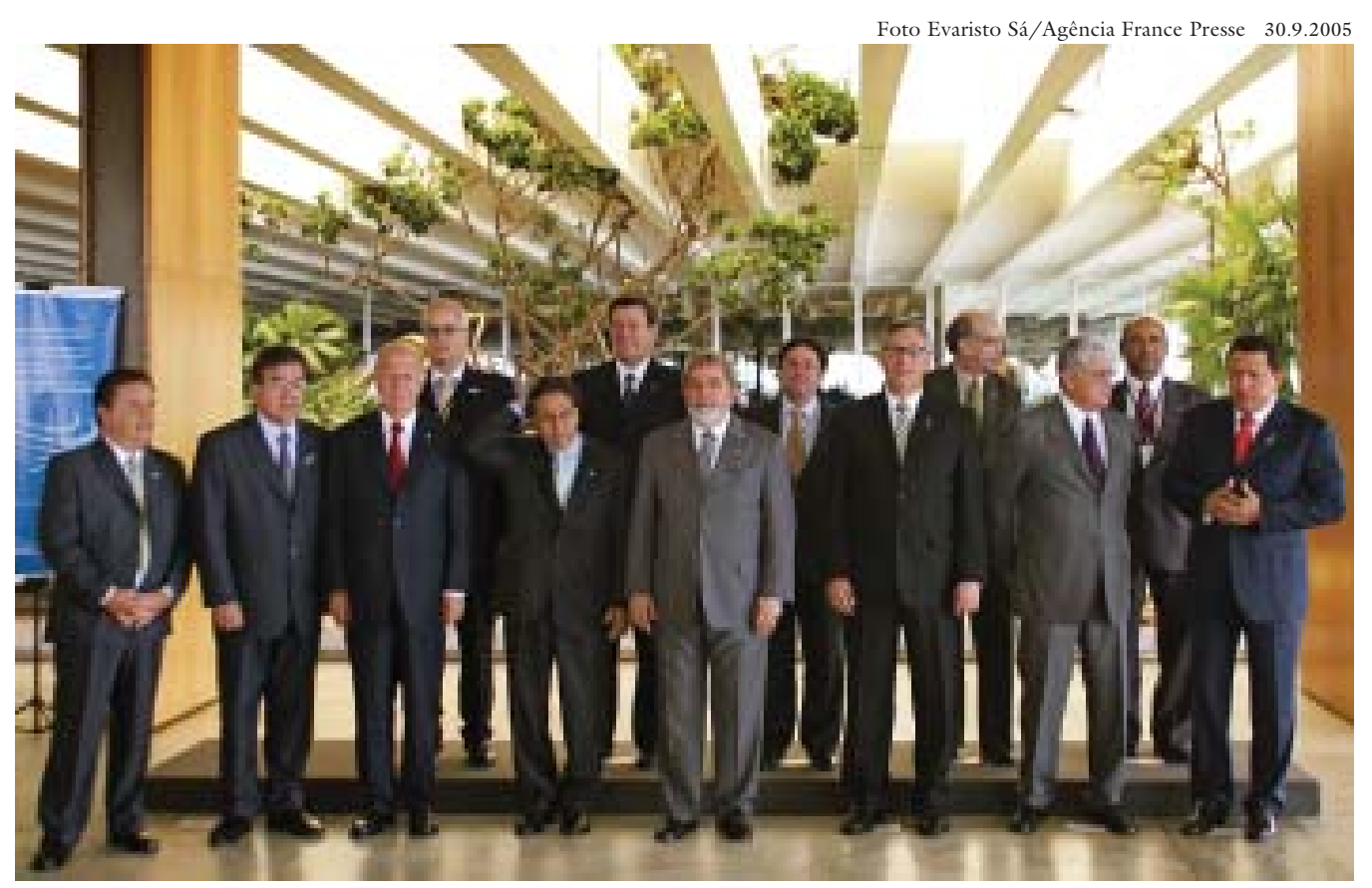

Da esquerda para direita, em pé: O presidente da Comissão de Representantes Permanentes do Mercosul, Eduardo Duhalde; o presidente do Paraguai, Nicanor Duarte Frutos; do Chile, Ricardo Lagos; do Peru, Alejandro Toledo; do Brasil, Luiz Inácio Lula da Silva; da Bolívia, Eduardo Rodríguez; do Equador, Alfredo Palacios e da Venzuela, Hugo Chávez, posam para a foto oficial da Comunidade Sul-americana das Nacões, no dia 30 de setembro de 2005, em Brasília. Atrás, da esquerda para direita: o vice-chanceler da Argentina, Jorge Taiana; o vice-presidente do Uruguai, Nin Novoa; o vice-presidente da Colômbia, Francisco Santos; o ministro de Assuntos Exteriores da Guiana, Rudolph Insanally e o embaixador do Suriname para Brasil, Nihalchand Sonr.

Malgrado a importância deste inventário programático, a reunião de Cuzco fez-se notar pela preocupação com os projetos de natureza econômica e, sobretudo, com os instrumentos para compatibilizar os distintos processos de integração em curso na região.

Assim, a Casa propugna a aproximação entre o Mercosul e a Comunidade Andina de Nações (CAN), que deve expressar-se através de numerosas iniciativas. As mais importantes seriam o fortalecimento dos vínculos institucionais pelo mecanismo de associação recíproca, com inclusão do Chile, Guiana e Suriname; e o estabelecimento de um calendário de reuniões dos órgãos-espelho do Mercosul e da CAN.

As secretarias da CAN e do Mercosul fariam um levantamento dos acordos já firmados pelas respectivas instituições nas áreas política e social, para que se possa examinar a possibilidade de estendê-los a todos os países da América do Sul.

As secretarias da Associação Latino-americana de Desenvolvimento e Integração (Aladi), da CAN e do Mercosul redigiriam, até março de 2006, uma lista de sugestões sobre o aprofundamento e a convergência dos acordos de 
complementação econômica entre os países da América do Sul. Estas sugestões deveriam compreender o objetivo de formatar uma zona de livre comércio sulamericana, dispondo de uma cobertura mínima de $90 \%$ do universo tarifário ${ }^{1}$. Além disso, seria criado um grupo técnico para recomendar medidas relativas a simplificação dos trâmites alfandegários, e o reconhecimento mútuo em matéria de normas técnicas e sanitárias.

Seriam realizadas rodadas sul-americanas de negócios para melhor aproveitar os acordos de complementação econômica assinados entre os países sulamericanos.

Igualmente, seria realizada reunião sobre facilitação do comércio, integração da produção e definição de eixos de integração e desenvolvimento das regiões fronteiriças.

A Corporação Andina de Fomento (CAF) e a Aladi elaborariam em conjunto com os bancos nacionais de fomento, estudos sobre o financiamento da integração física dos transportes, energia e comunicações na América do Sul concedendo especial atenção à utilização ampliada do Convênio de Crédito Recíproco (CCR).

Seria organizado um seminário sobre mecanismos de projeção financeira da Casa para debater, entre outros temas, a possibilidade de criação de um Banco Sul-americano de Desenvolvimento, e o estreitamento das relações entre as instituições regionais e nacionais existentes voltadas ao fomento do desenvolvimento e ao financiamento de projetos de integração.

Após dez meses de secretariado, exercido pelo Peru, o Brasil assume a condução do novo bloco a partir da Cúpula de Brasília, realizada em fins de setembro de 2005. Apesar das ausências - justificadas ou não - de alguns Chefes de Estado (Argentina, Colômbia, Uruguai etc.), a reunião serviu para firmar uma iniciativa que parecia fadada ao fracasso.

Contudo, no transcorrer da cerimônia de encerramento do evento, que justamente em razão de seu caráter solene e formal havia sido aberta à imprensa, o Presidente Chávez protagonizou um incidente revelador da natureza da proposta brasileira. Como o texto final a ser assinado pelos presidentes ou seus representantes especificava que "a Comunidade Sul-americana de Nações estabelecerse-á com base na institucionalidade existente", Chávez informou - publicamente e ao vivo - que "a Venezuela não dá como aprovada, e sequer foi debatida, a estrutura institucional da comunidade". Portanto, "não aceitamos que se diga que há uma estrutura aprovada" ${ }^{2}$.

A aparente diatribe chavista suscita, de fato, ao menos duas questões essenciais. A primeira diz respeito à compatibilidade entre os esquemas integracionistas vigentes e a Casa. Negada constantemente pelo Brasil, o fortalecimento da Casa resultará inevitavelmente num ainda maior enfraquecimento do já cambaleante Mercosul. Mais ainda, Chávez opõe-se tanto ao modelo Mercosulino quanto ao da CAN como fonte de inspiração para a Casa. Ao liberalismo mercantil dos dois 
primeiros, o dirigente venezuelano pretende opor uma integração social e política que atenda às necessidades dos povos, e não seja um mero acerto empresarial ${ }^{3}$.

Ao perceber que o modelo institucional é um reflexo dos objetivos perseguidos pela integração, Chávez se insurge contra esquemas que "condenariam nossa região ao fracasso e jogariam nosso povo de abismo em abismo". Ou seja, a institucionalização não é, como reiteram constantemente todas administrações brasileiras - inclusive a atual - que se sucederam desde a criação do Mercosul, uma questão menor a interessar os acadêmicos ingênuos e os juristas, mas elemento primordial que concede consistência, profundidade, seriedade e irreversibilidade ao processo.

A outra lição do incidente é a confirmação do processo de construção de consensos da integração sul-americana. De fato, há temas de importância crucial que são incluídos nos documentos sem que se faça uma discussão prévia pelos Chefes de Estado. A burocracia diplomática se auto-incumbe de responsabilidades políticas incompatíveis com suas funções. Esta forma de proceder é percebida como natural, a ponto de o Itamaraty propor um texto sobre o qual não havia acordo, pois não ocorrera debate, criando imenso constrangimento público aos Presidentes, especialmente o anfitrião.

O imenso risco assumido pela diplomacia brasileira não pode ser explicado por suposta falta de preparo ou irresponsabilidade de seus quadros. Trata-se, isto sim, de vontade deliberada e constante de manter os esquemas de integração no mais exclusivo plano do voluntarismo político e na sua mais absoluta dimensão comercial. Esta é a alma da Casa na perspectiva brasileira. Contra ela, surgiu na reunião de Brasília uma outra concepção que parece reunir a maioria dos Estados sul-americanos.

Todavia, desde 2000, há um movimento para dar substância à integração comercial por meio da criação de infra-estrutura energética, em comunicações e em transporte. Com efeito, o Brasil concede uma especial atenção aos projetos concretos que buscam a integração física da América do Sul. É neste contexto que se insere a Iniciativa para a Integração da Infra-estrutura Regional Sul-americana (Iirsa $)^{4}$. O projeto procura definir prioridades entre dois ou mais Estados nas áreas de comunicações, energia e transportes.

A delicada questão do financiamento deve ser resolvida, no essencial, com recursos financeiros da própria região. Ora, a maioria dos países não dispõe de capacidade de investimento. Por esta razão, o Banco Nacional de Desenvolvimento Econômico e Social (BNDES) criou um Departamento para a Integração Sul-americana encarregado de analisar a viabilidade dos projetos e lhes conceder suporte financeiro.

Um dos projetos - sonho acalentado desde a época dos bandeirantes começa a materializar-se. Com efeito, em 8 de setembro de 2005, Lula e o Presidente peruano Alejandro Toledo deram início à construção da Estrada InterOceânica que ligará a cidade brasileira de Assis Brasil a três portos peruanos, 
entre eles o Puerto San Juan. Pela primeira vez, haverá uma rota ligando o Atlântico e o Pacífico. Ela permitirá o transporte a um custo menor das exportações brasileiras do Centro-Oeste em direção dos mercados asiáticos ${ }^{5}$.

Parecem surgir, de outra parte, as premissas de uma estratégia energética sul-americana. Um primeiro projeto foi concluído com a assinatura, em 29 de setembro de 2005, de um acordo entre a companhia petrolífera venezuelana PDVSA e a Petrobras, objetivando a construção de uma refinaria de petróleo no porto de Suape (Pernambuco). Com um investimento orçado em mais de US\$ 2 bilhões de dólares, esta iniciativa aponta para a constituição de um anel energético reunindo os Estados produtores sul-americanos, que abrangerá o conjunto de etapas de produção (extração, refino e comercialização) de produtos energéticos e, particularmente, a constituição de uma rede sul-americana de gasoduto ${ }^{6}$.

Caso exitosos, estes projetos serão instrumentos potentes de aumento de comércio. Eles contemplam a velha idéia de que só existe integração econômica quando existem negócios. Até que se concretizem, e mesmo quando reais, a que tipo de integração serviriam? O espectro reflexivo capaz de responder esta pergunta é o mesmo instrumento que serve à questão central deste artigo: o que esperar do Mercosul no atual contexto latino-americano?

\section{O Mercosul na sala de espera}

Graças à própria denominação, o Mercado Comum do Sul (Mercosul) se auto-atribuiu, no momento de seu nascimento a 26 de março de 1991, uma missão ambiciosa: fazer com que surgisse, pela primeira vez ao Sul do Equador, um mercado comum que permita a circulação sem entraves da produção, do capital e dos trabalhadores. Muito já se escreveu sobre sua evolução histórica, econômica, política e jurídica.

Numerosas desinteligências produziram imenso impacto na condução do processo de construção do Mercosul, que desfruta de pouco peso político e tímida atenção de parte dos governos e, em particular, do Brasil. Embora reconhecendo que a resistência à hegemonia unipolar nas Américas depende da consolidação do projeto de integração no Cone Sul, o Brasil de Lula resiste, como resistiram as administrações anteriores, à consolidação do Mercosul como uma organização internacional regional, e referenda a simples justaposição de propostas nacionais inconciliáveis. Opera um desserviço lamentável à construção de uma perspectiva regional consistente que, se expressa em políticas regionais tangíveis nos mais distintos âmbitos, representaria um avanço histórico notável para nossos povos.

O Brasil também é conivente com uma estrutura institucional cara, ineficiente e de curtos horizontes. Pouco se refere na doutrina especializada os custos da intergovernamentalidade. Um exército de funcionários desloca-se, a cada semestre, para negociar em mais de duzentos foros especializados, compondo um quebra-cabeças em que cada peça é feita sem considerar o formato da outra. Há dezenas de foros tratando dos mesmos temas. Há assimetrias profundas, qualita- 


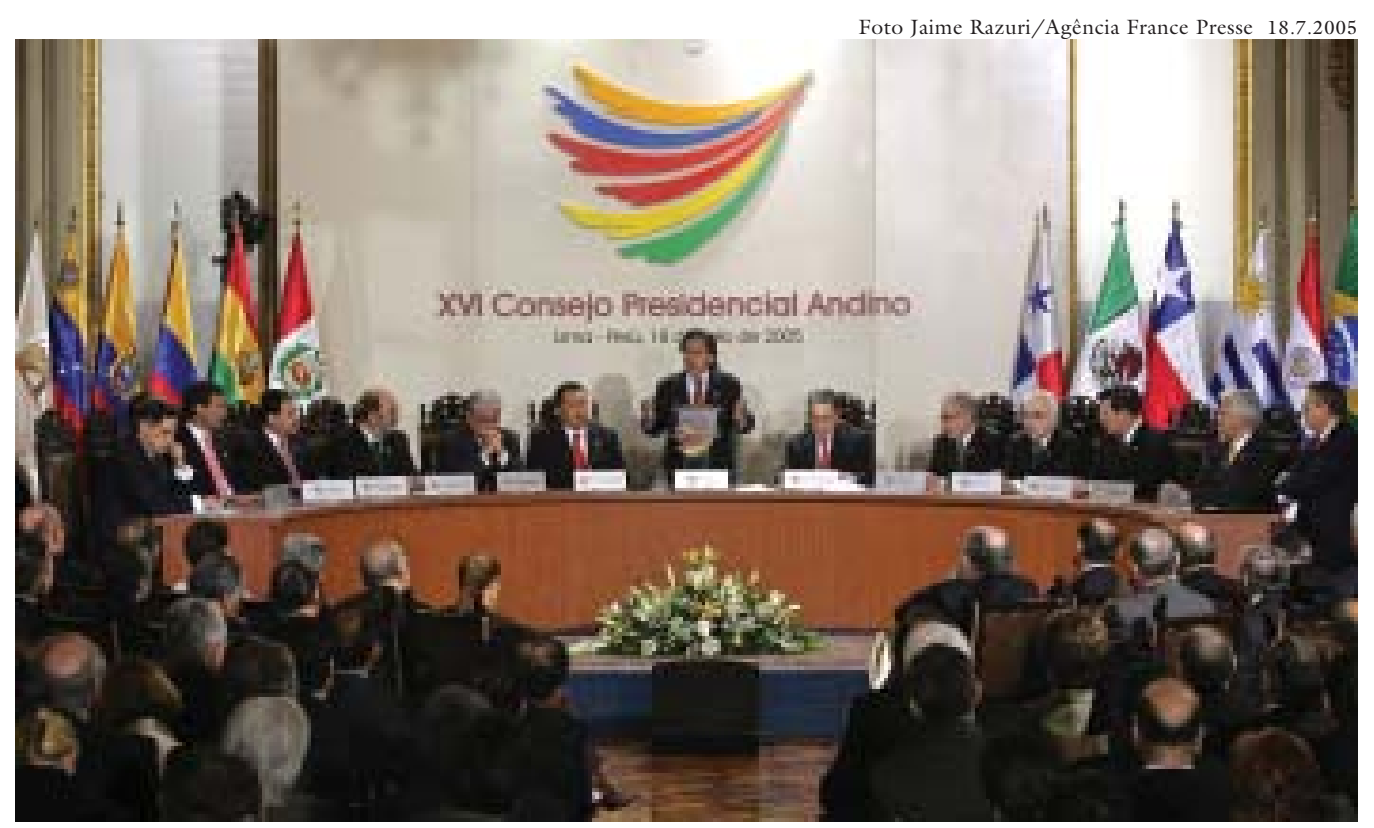

Presidentes de países andinos e enviados sul-americanos do bloco comercial do Mercosul, participam da abertura da XVI Reunião da Comunidade Andina de Nações (CAN), realizada em 18 de julho de 2005, em Lima, no Peru. Ao centro, Alejandro Toledo.

tivas e quantitativas, entre as Delegações presentes. É débil a coordenação ministerial em cada país, e quase inexistente articulação entre os órgãos do próprio Mercosul. A eficácia deste enorme esforço negociador é parca. Tão pouca é a qualidade técnica do que se elabora, que a maioria das decisões sequer tem condições de ser aplicada.

Por outro lado, além da pouca eficiência, a escassa permeabilidade dos patéticos três órgãos decisórios do Mercosul (Conselho, Grupo e Comissão de Comércio) em relação ao setor privado e à sociedade civil, revela uma cultura autoritária inaceitável em governos progressistas. A confidencialidade de imenso volume de documentos esconde a lentidão e o despreparo dos negociadores, que ostentam uma espécie de "complexo de Aladi”. Refém de uma visão antiquada da integração econômica, o Mercosul patina em merecido descrédito.

A associação de novos Estados (Colômbia, Equador, Peru e Venezuela juntaram-se à Bolívia e Chile) e o acordo com a CAN constituem igualmente uma preocupante sobreposição de processos. O diferente grau de envolvimento que decorre de um estatuto de associação à la carte causa turbulência institucional e, em breve, causará graves problemas jurídicos. Economicamente, o estatuto de associação é irrelevante.

$\mathrm{Na}$ hipótese de a Casa não conhecer o mesmo destino funesto da Alcsa, a partir deste momento torna-se impossível avaliar a evolução do Mercosul abstraindo a construção deste arranjo subcontinental. Se ele persistir como estrutura flexível de cooperação, verifica-se uma redundância em relação à Casa, e logo as agendas decisórias rasparão produzindo faíscas. A única hipótese que restaria ao 
Mercosul seria transformá-lo no mercado comum ao qual se havia proposto em 1991. Ora, as dificuldades da atual união aduaneira deixam poucas esperanças de que isto venha a ocorrer.

A tendência do Mercosul é retornar ao modelo de uma simples zona imperfeita de livre comércio. O recorrente dilema aprofundamento versus alargamento adquire atualidade e pertinência. Tal como ocorreu em 1994, quando o Mercosul se preparava a definir sua institucionalização e surgiu a Alcsa, novamente quando há a possibilidade de uma refundação do bloco a partir de uma nova institucionalidade, inclusive dotado de um Parlamento, a Casa surge como alternativa, embaralhando o jogo.

Apesar de ser considerado como o eixo de seu relacionamento na América do Sul, as relações argentino-brasileiras sofrem rudes golpes com nossa pretensão na reforma do Conselho de Segurança (CS) da ONU e com o lançamento da Casa. Buenos Aires não aceita o papel secundário - dirão alguns, subalterno que a diplomacia brasileira lhe reserva. Portanto, há constante descompasso na região, conduzindo os dois países a adotar estratégias contraproducentes.

Como era de se esperar, a proposta brasileira suscita no início dúvidas, que se transformam rapidamente em inquietações, que desembocam em oposições. Aos processos de intenções mesclam-se críticas sobre os objetivos e procedimentos da Casa. Além do conteúdo das criticas, é necessário enfatizar a identidade de seus emitentes.

As reservas provinham, no início, essencialmente de Buenos Aires, que sofre com o ativismo diplomático de Lula e sua equipe. Contudo, a partir da Cúpula de Brasília, a proposta da Casa se vê ultrapassada pela esquerda. Não mais em razão de um amor próprio nacional ferido, como no caso argentino, mas em decorrência da contestação ao modelo proposto.

De qualquer maneira, o Mercosul é o grande derrotado da estratégia diplomática de Lula. Apesar do reconhecimento da necessidade de questionar as investidas dos Estados Unidos - tal como se apresenta a proposta da Área de Livre Comércio das Américas (Alca) - o Brasil não deposita seus interesses no fortalecimento do Mercosul. Ao contrário, este alcança unicamente uma dimensão tática, enquanto a Casa se transforma em uma escolha estratégica.

Tratar-se-ia do dilema entre o Brasil potência e o Brasil integrado? Duas velocidades continentais evoluem: a verdadeira prioridade da abrangência sulamericana, que agrega poder e influência, e constitui um verdadeiro contraponto ao fantasma da Alca; e a da integração sub-regional, mantida em banho-maria. No fundo, o Mercosul parece ser um instrumento de inserção internacional assentado na visão dos outros sobre nós mesmos, mantendo incólume a margem de discricionariedade brasileira, sem prazos razoáveis, tampouco maiores concessões e compromissos.

O projeto da Casa é exatamente o contrário de um mercado comum, e em lugar de sobrepor, opõe alargamento e aprofundamento. Trata-se de um mode- 
lo puramente estatal e comercial, ao passo que o Mercosul poderia ser um mecanismo de integração profunda, inspirado por preocupações sociais e democráticas.

Apesar de todos os seus defeitos, em particular o profundo antiamericanismo e a apropriação retórica do sonho bolivariano, Chavez referiu um ponto essencial: a incapacidade da integração latino-americana de produzir uma institucionalidade que lhe confira permanência e eficiência, e viabilize estratégias comuns em benefício das sociedades latino-americanas. As palavras que ele referiu, fracasso e institucionalização, constituem dois tabus da dogmática integração latino-americana. Admiti-las em um necessário debate democrático talvez possa ser a chave para que o Mercosul não seja apenas uma dependência da Casa.

\section{Notas}

1 A criação de uma zona de comércio sul-americana nos termos propostos foi referendada na Cúpula de Brasília. Todavia, ao contrário da posição defendida pelo Chile, não foi estabelecida uma data-limite para atingi-la. Portanto, ausentes um calendário de desgravamento e indefinido um método de trabalho, este projeto junta-se aos demais em sua condição de mera expressão de uma vontade política com fins de comunicação midiática.

2 Após tensos momentos, finalmente foi aprovada a Declaração Final com o compromisso brasileiro de retomada das discussões na próxima Cúpula do Mercosul, a realizar-se no início de dezembro de 2005 em Montevidéu.

3 O presidente Nicanor Duarte, do Paraguai, aproveitou a oportunidade para ser o porta-voz das nações mais pobres da região e declarou que não haverá uma nova integração baseada no modelo do Mercosul pois este ignora as assimetrias econômicas existentes na América do Sul.

$4 \mathrm{O}$ governo atual herdou este programa da precedente administração, pois a primeira reunião da Iirsa ocorreu em Brasília em setembro de 2000. Para mais informações consultar o sitio http://www.iirsa.org.

5 Bloqueada durante muito tempo no Banco Mundial em razões dos supostos problemas ambientais que provocaria a construção da estrada, o financiamento finalmente foi garantido pelo BNDES. O corredor Santos/ Puerto San Juan terá uma extensão de 3.800 $\mathrm{km}$ sendo $1.100 \mathrm{~km}$ em território peruano. Seu custo total é estimado a US\$ 892 milhões de dólares sendo US\$ 700 milhões financiados pelo BNDES. Enfim, foi constituído um pool de empresas brasileiras de grandes obras públicas encarregadas da construção. Portanto, o financiamento do BNDES - criticado por parte da oposição - será concedido essencialmente a empresas brasileiras.

6 Há também a possibilidade de criação da Petrosul, que reuniria, além das empresas citadas, a YPF argentina.

RESUMO - A PROPOSTA brasileira de criação de uma Comunidade Sul-americana de Nações (Casa) coloca em questão a própria existência do Mercosul nos moldes em que ele havia sido projetado em 1991. As recorrentes crises do Mercosul giraram até o momen- 
to em torno do modelo e do ritmo preconizados para a integração platina. A partir do surgimento da Casa é possível perceber os sinais de incompatibilidade entre os sistemas da Bacia do Prata e o sub-continental, especialmente em razão de uma vertente econômica deste último. O fato de o Brasil considerar o Mercosul simplesmente como um desafio tático para alcançar o objetivo estratégico representado pela Casa indica uma posição que busca afirmar um Brasil potência em detrimento de um Brasil integrado.

PALAVRAS-CHAVE: Mercosul, Casa, Crise, Liderança, Integração.

ABSTRACT - THE BRAZILIAN proposal to create the South American Community of Nations (Casa) calls into question the very existence of Mercosul as it was conceived in 1991. Mercosul's recurring crises have revolved to this day around the model and pace propounded for integration of the river Plate countries. After the emergence of Casa, however, one can see signs of incompatibility between the river Plate and the subcontinental systems, particularly because of the latter's economic bias. The fact that Brazil considers Mercosul merely a tactical challenge conducive to attaining the strategic goal represented by Casa indicates a position supportive of a powerful Brazil to the detriment of an integrated Brazil.

Key-words: Mercosul, Casa, Crisis, Leadership, Integration.

Ricardo Seitenfus é doutor em Relações Internacionais pelo Institut Universitaire des Hautes Études Internationales da Universidade de Genebra. Professor titular na Universidade Federal de Santa Maria e diretor da Faculdade de Direito de Santa Maria (Fadisma). Suas mais recentes obras são: Relações internacionais (São Paulo, Manole, 2004), e Manual das organizações internacionais (4⿳亠口了 ed., Porto Alegre, Livraria do Advogado, 2005). @ - independência@viavale.com.br

Recebido em 6.10 .05 e aceito em 10.10.05. 